\title{
Hypersexuality, gender, and sexual orientation: A largescale psychometric survey study
}

\begin{abstract}
Criteria for Hypersexual Disorder (HD) were proposed for consideration in the DSM-5 but ultimately excluded for a variety of reasons. Regardless, research continues to investigate hypersexual behavior (HB). The Hypersexual Behavior Inventory (HBI) is one of the most robust scales assessing HB, but further examination is needed to explore its psychometric properties among different groups. Therefore, the aim of the present study was to examine the generalizability of the HBI in a large, diverse, nonclinical sample ( $\mathrm{N}=18,034$ participants; females $=6132 ; 34.0 \% ; M_{\text {age }}=33.6$ years, $\left.S D_{\text {age }}=11.1\right)$ across both gender and sexual orientation. Measurement invariance testing was carried out to ensure gender- and sexualorintation based comparisons were meaningful. Results demonstrated when both gender and sexual-orientation were considered (i.e., heterosexual males vs. LGBTQ males vs. heterosexual females vs. LGBTQ females), LGBTQ males had significantly higher latent means on the HBI factors. Results also demonstrated LGBTQ males had the highest scores on other possible indicators of hypersexuality (e.g., frequency of masturbation, number of sexual partners, or frequency of pornography viewing). These findings suggest LGBTQ males may be a group most at risk of engaging in hypersexual behavior and LGBTQ females are at a higher risk of engaging in hypersexual activities due to coping problems. Given the largescale nature of the study, the findings significantly contribute to the currently growing body of literature on hypersexuality.
\end{abstract}

Keywords: gender, hypersexuality, measurement invariance, pornography, sexual orientation 


\section{Hypersexuality, gender, and sexual orientation: A largescale psychometric survey study}

\section{INTRODUCTION}

Hypersexual behavior (HB) is generally considered non-paraphilic dysregulated sexual behavior consisting of diminished control over sexual urges, fantasies, and behaviors, accompanied by negative consequences and significant personal distress for at least six months (Kafka, 2010). Despite Kafka's (2010) specific diagnostic criteria, HD was not included in the latest edition of the Diagnostic and Statistical Manual of Mental Disorders (DSM-5; American Psychiatric Association, 2013) due to the lack of high quality studies examining hypersexuality and a variety of other reasons (e.g., Kafka, 2010; Reid, 2015; Reid \& Kafka, 2014; Stark, Kruse, Klucken, Strahler, \& Wehum-Osinsky, 2017). Furthermore, most studies have focused on male samples with HB, with females often being neglected (e.g., Dhuffar \& Griffiths, 2016; Montgomery-Graham, 2017; Reid, Garos, \& Carpenter, 2011; Yeagley, Hickok, \& Bauermeister, 2014). The role of sexual orientation in hypersexuality research is another relevant demographic factor that has received little attention in research to date with a few exceptions (e.g., Cooper, Delmonico, \& Burg, 2000; Missildine, Feldstein, Punzalan, \& Parsons, 2005). Therefore, the aim of the present study was to further investigate hypersexuality and its possible indicators alongside gender and sexual orientation utilizing a large-scale sample in hopes of adding to the existing knowledge-base of HB. Such information can aid researchers in examining the utility of classifying $\mathrm{HB}$ as a possible diagnosis among psychiatric disorders.

Hypersexual behaviors are typically characterized as non-paraphilic and can manifest in several different forms such as masturbation, sexual behavior with consenting adults, cybersex, pornography use, cybersex, telephone sex, visiting strip clubs, and/or other sex-related behaviors (Kafka, 2010; Wéry et al., 2016). According to previous studies, there is a $70 \%$ prevalence rate of 
uncontrollable masturbation in a clinical sample of males with paraphilias and paraphilia-related disorders. Furthermore, $50 \%$ of these males report pornography dependence which was positively associated with telephone sex dependence and compulsive masturbation (Kafka \& Hennen, 1999). Recent studies report similar findings. For instance, in a study by Reid, Carpenter and Lloyd (2009), more than half of the males receiving clinical treatment for hypersexual behaviors reported compulsive masturbation (59\%) and pornography dependence (51\%), while one-fifth of them reported extra-marital affairs (21\%). The DSM-5 field trial for hypersexual disorder also found compulsive masturbation (78.3\% of participants) and excessive pornography consumption (81.1\% of participants) to be the most frequently endorsed problematic sexual behavior (Reid et al., 2012). Therefore, masturbation and pornography use appear to be two important manifestations of hypersexuality with repeated visits to strip clubs being an alternative form of live visual pornography (Kafka, 2010).

To date, epidemiologic data regarding hypersexuality are sparse, and most published studies have mainly focused on HB among males (e.g., Kinsey, Pomeroy, \& Martin, 1948; Kraus, Martino, \& Potenza, 2016; Levaque, Sawatsky, \& Lalumiére, 2016), with a paucity of studies investigating female HB (e.g., Dhuffar \& Griffiths, 2014; Klein, Rettenberger, Boom, \& Briken, 2014). Moreover, studies examining gender differences have proved inconclusive. For instance, some studies (e.g., Langström \& Hanson, 2006; Winters, Christoff, \& Gorzalka, 2010) suggest that males are more likely to report hypersexuality-related behaviors, while other studies (e.g., Seegers, 2003) suggest that females report more hypersexuality-related behaviors than males.

There is a paucity of studies examining HB among sexual minority groups (i.e., lesbian, gay, bisexual, transgender, and queer communities - LGBTQ) - presumably due to the relatively small proportion of LGBTQ individuals in the general population (i.e., Cooper et al., 2000; Missildine et al., 2005). According to these studies, higher levels of sexual compulsivity appear 
to occur among LGBTQ individuals than heterosexuals. These are preliminary findings, but there are possible explanations as to why LGBTQ individuals may have higher levels of HB. Firstly, sexual content is easily accessible to everyone online, therefore, it is possible that this accessibility makes it easier for LGBTQ individuals to engage in risky sexual behavior (e.g., problematic pornography use or finding casual sexual partners online) (Montgomery-Graham, 2017; Parsons, 2005; Parsons, Kelly, Bimbi, Muench, \& Morgenstern, 2008). Secondly, there is evidence suggesting that experiencing homophobia - even to a small extent within a given society - could lead to the internalization of this homophobic experience which in turn leads to anxiety, romantic relationship development, and sexuality-related problems, potentially causing hypersexual tendencies (Montgomery-Graham, 2017; Muench, \& Parsons, 2004). Despite these existing theories and evidence, further research is needed in the field of hypersexuality among different sexual orientations.

Several scales have been developed to assess hypersexual behavior (for comprehensive reviews, see Hook, Hook, Davis, Worthington, \& Penberthy, 2010; Montgomery-Graham, 2017; Womack, Hook, Ramos, Davis, \& Penberthy, 2013). One of the most reliable, valid, and frequently used self-report scales being the Hypersexual Behavior Inventory (Reid, Garos, \& Carpenter, 2011) which has been used in numerous studies (e.g., Marshall \& Briken, 2010; Montgomery-Graham, 2017; Stewart \& Fedoroff, 2014). The three-factor model of HBI has also shown strong psychometric properties in terms of high internal consistency, high test-retest reliability, confirmatory factor analysis and construct validity in English and non-English speaking samples and among males and females (Klein, Rettenberger, Boom, \& Briken, 2014; Reid et al., 2011; Yeagley et al., 2014). The results of the previous validation studies of the HBI are detailed in Table 1. Moreover, the HBI has been demonstrated to have strong concurrent, 
criterion, discriminant, and clinical validity in several previous studies (e.g., MontgomeryGraham, 2017; Reid, Dhuffar, Parhami, \& Fong, 2012; Yeagley et al., 2014).

Although this scale has a strong theoretical background and robust psychometric properties, little scientific attention has been paid to the application of large samples to examine whether men and women, or heterosexual and LGBTQ individuals, respond to the HBI similarly or whether they have gender- or sexual orientation-based differences in their response patterns. In the literature there are conflicting findings (e.g., Cooper et al., 2000; Winters et al., 2010) as to whether gender or sexual orientation have more influence on the development and maintenance of hypersexuality. Therefore, the aim of the present study was to systematically investigate these potential differences across different subgroups (males vs. females, heterosexual vs. LGBTQ individuals) via tests of measurement invariance. These tests are preferable to other group-based comparisons because, instead of scale scores, fully latent variables are used which are naturally corrected for measurement errors (Marsh \& Hau, 2007). Moreover, the generalizability of the findings can also be verified across distinct samples.

\section{METHOD}

Participants and procedure

The present research was conducted in accordance with the approval of the Institutional Review Board of the research team's related university and carried out under the Declaration of Helsinki. The research was conducted via an online questionnaire that took approximately 30 minutes to complete. Data collection occurred in January 2017. Prior to enrollment, participants received detailed information about the study, read and provided informed consent, and indicated being 18 years or older. Participants were invited to take part in the study via one of the largest Hungarian news portals. A total of 31,883 participants visited the website with 7,256 individuals 
declining to participate in the study. A further 145 individuals were removed because they were under-aged, and 110 individuals were removed for inconsistent survey responses.

Out of 24,372 participants, 18,034 participants had sexual experiences before, therefore, they filled out the Hypersexual Behavior Scale. Consequently, a total of 18,034 participants $($ females $=6,132,34.0 \%$, males $=11,792,65.4 \%$, other $=110,0.6 \%)$ aged between 18 and 76 years $\left(M_{\text {age }}=33.6, S D_{\text {age }}=11.1\right)$ took part in the study. Of these participants, 9,727 lived in a capital city (53.9\%), 2,760 in county towns (15.3\%), 3,868 in towns $(21.4 \%)$, and 1,679 in villages $(9.3 \%)$. Regarding their sexual orientation, 15,080 were heterosexual $(83.6 \%), 1,724$ were heterosexual with homosexuality to some extent (9.6\%), 486 were bisexual $(2.7 \%), 121$ were homosexual with heterosexuality to some extent $(0.7 \%), 458$ were homosexual (2.5\%), 20 were asexual $(0.1 \%), 93$ were unsure about their sexual orientation $(0.5 \%)$, and 52 indicated the "other" option $(0.3 \%)$. In order to simplify the analysis of sexual orientation-based groups, the research team merged the "heterosexual with homosexuality to some extent", the "bisexual", the "homosexual with heterosexuality to some extent", the "homosexual", the "asexual" and the "unsure” groups into a "LGBTQ” group.

\section{Measures}

Hypersexual Behavior Inventory (HBI; Reid et al., 2011). The HBI is a 19-item scale which assesses hypersexual behavior via three dimensions. Participants indicated their answers on a five-point Likert scale $(1=$ never; $5=$ very often $)$. The coping factor $(\alpha=.86$; seven items; e.g., "Sex provides a way for me to deal with emotional pain I feel.") refers to sex and sexual behaviors as a response to emotional distress such as sadness or daily life worries. The control factor $(\alpha=.82$; eight items, e.g., "I feel like my sexual behavior is taking me in a direction I don't want to go.") refers to perceived diminished ability to self-regulate sexual fantasies, urges and 
behaviors. The consequences factor $(\alpha=.75$; four items, e.g., "My sexual activities interfere with aspects of my life, such as work or school.”) refers to the diverse consequences of sexual thoughts, urges and behaviors such as sexual activities interfere with educational and occupational duties or interpersonal relationships. The HBI was translated into Hungarian on the basis of Beaton, Bombardier, Guillemin and Ferraz's (2000) protocol.

Sexuality-related questions. In addition to the demographic questions (e.g., gender, age, sexual orientation, etc.) further topic relevant questions were asked, including number of sexual partners: "How many sexual partners have you had in your life (in a relationship or out of a relationship)?" (16-point scale, $1=$ "0 partner", 16 = "more than 50 partners"); number of casual sexual partners: "How many casual sexual partners have you had in your life?” (16-point scale, $1=$ "0 partner", $16=$ "more than 50 partners"); frequency of sex with the partner: "Last year, how often did you have sex with your partner?" (10-point scale, $1=$ "never", $10=$ "6 or 7 times a week"); frequency of sex with casual partners: "Last year, how often did you have sex with a casual partner?" (10-point scale, $1=$ "never", $10=$ "6 or 7 times a week"); frequency of masturbation: "Last year, how often did you masturbate?" (10-point scale, 1 = "never", $10=$ "6 or 7 times a week"). Respondents were also asked about the frequency of viewing pornographic videos online (10-point Likert scale, $1=$ "never", $10=$ "6 or 7 times a week") and the time spent accessing pornography per session: "When you watch porn, how much time do you spend with it per each session?” (from "0 minutes" to "180 minutes").

Statistical analysis

For the statistical analysis, SPSS 21 and Mplus 7.3 (Muthén \& Muthén, 1998-2015) were used. Confirmatory factor analysis (CFA) was used to assess the dimensionality of the Hypersexual Behavior Inventory. The items had severe floor effects (on the basis of skewness 
and kurtosis), therefore, they were treated as categorical indicators and the mean- and varianceadjusted weighted least squares estimator (WLSMV) was used (Finney \& DiStefano, 2006). In the structural assessment, commonly used goodness of fit indices (Brown, 2015; Kline, 2011) were observed (Bentler, 1990; Brown, 2015; Browne \& Cudeck, 1993; Hu \& Bentler, 1999; Schermelleh-Engel, Moosbrugger, \& Müller, 2003; Tabachnick \& Fidell, 2013): the Comparative Fit Index (CFI; $\geq .95$ for good, $\geq .90$ for acceptable), the Tucker-Lewis index (TLI; $\geq .95$ for good, $\geq .90$ for acceptable), and the Root-Mean-Square Error of Approximation (RMSEA; $\leq .06$ for good, $\leq .08$ for acceptable) with a $90 \%$ confidence interval.

To test structural invariance between groups based on gender (male vs. female), sexual orientation (heterosexual vs. LGBTQ) and combination of gender and sexual orientation (heterosexual males vs. LGBTQ males vs. heterosexual females vs. LGBTQ females), several multi-group CFAs were carried out (Meredith, 1993; Tóth-Király, Bőthe, Rigó, \& Orosz, 2017; Vandenberg \& Lance, 2000). First, the models were estimated freely for both male and female subgroups. Second, nested models with increasingly constrained parameters were estimated: (i) factor loadings and thresholds were freely estimated (configural invariance), (ii) factor loadings were set to be equal (metric invariance), (iii) factor loadings and thresholds were set to be equal (scalar invariance), (iv) factor loadings, thresholds, and residual variances were constrained to be equal (residual invariance), (v) factor loadings, thresholds, uniqueness, and variance-covariances were constrained to be equal (latent variance and covariance invariance), and (vi) factor loadings, thresholds, residual variances, latent variance invariances, latent covariances and latent means were constrained to be equal (latent mean invariance). Testing invariance on higher levels (e.g., latent invariance and covariance invariance, latent mean invariance) can be relevant for the generalizability of the construct. When comparing the increasingly constrained models, relative 
change in fit indices were observed (Chen, 2007; Cheung \& Rensvold, 2002; Marsh et al., 2009): $\Delta \mathrm{CFI} \leq .010 ; \Delta \mathrm{TLI} \leq .010 ;$ and $\Delta \mathrm{RMSEA} \leq .015$

One-way analyses of variance (ANOVA) with Bonferroni post-hoc tests were conducted to investigate whether the gender and sexual orientation-based groups were different in their number of sexual partners, number of casual sexual partners, frequency of masturbation, frequency of viewing online pornographic videos, and the time spent with pornography use per session.

\section{RESULTS}

Measurement invariance

In order to ensure meaningful comparisons based on gender, sexual orientation, and gender-sexual orientation, measurement invariance was carried out to examine the factor structure of the HBI across two subgroups (i.e., male vs. female, heterosexual vs. LGBTQ), then across four subgroups (heterosexual male vs. LGBTQ male vs. heterosexual female vs. LGBTQ female). The results of the invariance analyses are shown in Table 3. Firstly, in step zero, the baseline models were estimated for both males and females, showing acceptable fit. Then, parameters were gradually constrained and changes in fit indices were observed. Although all $\chi^{2}$ test were significant, other fit indices ( $\triangle \mathrm{CFI}, \Delta \mathrm{TLI}, \triangle \mathrm{RMSEA})$ changed in the acceptable range, indicating gender invariance on the level of latent means. The results of the sexual orientationbased invariance testing were highly similar, indicating sexual orientation-related invariance on the level of latent means. In the case of the gender and sexual orientation-based invariance testing, all $\chi^{2}$ tests were significant. However, other fit indices did not decrease more than the recommended cut-off value, indicating gender-sexual orientation-based invariance on the level of 
latent variance-covariance matrix. Latent mean invariance could not be achieved in these groups, suggesting the presence of latent mean differences (Table 2).

When the latent means of the LGBTQ males were set to be zero for the purpose of identification, the inspection of the latent means revealed that all other groups' (LGBTQ females, heterosexual males and heterosexual females) latent means were significantly lower (differences ranging from -1.05 to -0.11) on all the three factors (coping, control, consequences). When the latent means of the heterosexual females were set to be zero, it was demonstrated that all other groups' latent means were significantly higher on all factors (differences ranging from 0.15 to 1.05). Only one non-significant difference was identified, in the case of the control factor where latent means of LGBTQ females and heterosexual males were not significantly different. In summary, LGBTQ males scored the highest, while heterosexual females had the lowest scores on each dimension of hypersexuality. In the case of LGBTQ females and heterosexual males, a more diverse pattern was evident. There was no difference in the control dimension, however, LGBTQ females scored higher on the coping dimension, while heterosexual males had higher scores on the consequences dimension. For the latent mean differences, see Table 3, and for a visual representation, see Figure 1.

Gender and sexual orientation-based comparisons

In the next step of the analysis, one-way ANOVAs with a Bonferroni post-hoc tests were conducted in order to investigate whether gender and sexual orientation-based groups differed in other possible indicators of hypersexuality (see Table 4). According to the results, LGBTQ males significantly differed from all the other groups on all dimensions, except for the frequency of having sex with casual partners. LGBTQ males had an average of ten sexual partners, while heterosexual males, LGBTQ females and heterosexual females had approximately seven sexual 
partners in their lifetime. Regarding casual sexual partners, LGBTQ males had eight to nine casual sexual partners, while the members of the other three groups had approximately three to five casual sexual partners. Regarding the frequency of having sex with the partner, LGBTQ males indicated the lowest frequency (approximately having sex two or three times a month), followed by heterosexual males (weekly), LGBTQ females (weekly), and heterosexual females (weekly). Although LGBTQ males had the highest frequency of having sex with casual sexual partners followed by heterosexual males, LGBTQ females and heterosexual females, the differences between the groups were small and in most of the cases they were not statistically significant.

LGBTQ males masturbated approximately two to five times a week, heterosexual males masturbated one to three times a week, LGBTQ females masturbated weekly, and heterosexual females masturbated two or three times a month. Regarding the frequency of pornography viewing, LGBTQ males viewed it two or three times a week, heterosexual males viewed it weekly, LGBTQ females viewed it monthly, and heterosexual women viewed it seven to eleven times in the last year. Considering the duration of pornography viewing per each occasion, LGBTQ males watched it approximately for 36 minutes per session, while heterosexual males watched it for 28 minutes, LGBTQ females watched it for 24 minutes, and heterosexual females watched it for 22 minutes. In summary, LGBTQ males had the highest number of sexual partners in their lifetime, had the highest number of casual partners, masturbated and watched pornography videos most frequently, and they spent the longest time with it each session.

\section{DISCUSSION}

The Hypersexual Behavior Inventory (HBI) has previously demonstrated robust psychometrics in terms of reliability and validity (e.g., Klein et al., 2014; Reid et al., 2011; 
Yeagley et al., 2014; Reid, Dhuffar, Parhami, \& Fong, 2012). According to the present study, the HBI had strong psychometric properties in terms of factor structure and measurement invariance along several subgroups. In the case of tests of invariance based on gender and sexualorientation, latent mean invariance was not achieved, indicating that the latent means of the groups were different with LGBTQ males having the highest latent means and they also reported highest scores regarding the other possible indicators of hypersexual behaviors on the HBI.

According to measurement invariance testing, if individual's gender or sexual orientation are considered separately, measurement invariance was achieved at the level of latent means, indicating that there were no latent means differences between males-females and heterosexualLGBTQ individuals. However, if gender and sexual orientation are considered together (i.e., heterosexual males, LGBTQ males, heterosexual females, and LGBTQ females), then the latent means of the respective groups differed. LGBTQ men and LGBTQ women had significantly higher latent means on the coping dimension than heterosexual men and heterosexual women. Thus, LGBTQ individuals use sex and sex-related fantasies and behavior in order to cope with their negative feelings or negative life events. It is plausible LGBTQ individuals may experience more negative feelings and emotions (such as anxiety, depression or stress) in relation to sexual orientation as others have noted (Parsons, Kelly, Bimbi, DiMaria, Wainberg, \& Morgenstern, 2008). Furthermore, their sexual orientation can sometimes be stigmatized and sex or sex-related activities can act as an effective way to reduce such feelings (Grubbs et al., 2017; MontgomeryGraham, 2017; Muench, \& Parsons, 2004).

Furthermore, the present results also demonstrated that LGBTQ men scored significantly higher than any other groups on the control and consequences dimensions. LGBTQ males had the lowest level of capability in controlling sexual urges and fantasies, and therefore, they experienced the negative consequences of their behavior most frequently. On the basis of 
previous preliminary findings (Muench \& Parsons, 2004; Parsons, 2005; Parsons et al., 2008), it is possible that the easy accessibility, infinite variety, and arguably inexhaustible amount of LGBTQ sexual content on the Internet could contribute to the uncontrollable engagement in risky sexual activities. According to Parsons et al. (2008), LGBTQ-oriented sexual venues and outlets (such as sex parties or sex websites) might make it easier for LGBTQ males at risk for developing hypersexuality to actually develop hypersexual behavior. They claim that the availability of sexual outlets functions similarly to the way in which higher incidences of problematic gambling appear in populations with elevated access to gambling opportunities (Volberg, 1994). However, it should be noted that heterosexual content is as available and accessible on the Internet as LGBTQ content. Therefore, this content can serve as a trigger for LGBTQ or heterosexual males and females who are also at risk of developing hypersexuality to actually developing hypersexuality.

From these findings, it can be concluded that LGBTQ men are a group most at risk of developing and maintaining hypersexual behavior. These results are in line with previous studies suggesting that hypersexuality is more prevalent among men than women, and more prevalent among LGBTQ men than heterosexual men (e.g., Cooper et al., 2000; Kafka, 2010; Langström \& Hanson, 2006; Missildine et al., 2005). Moreover, it is important to note that LGBTQ women are also a group at risk of engaging in sex or sex-related activities to cope with unwanted feelings and stress, and that this behavioral pattern can lead to serious consequences but in the long-term. According to previous literature (e.g., Grubbs et al., 2017), in addition to the subjective indicators of hypersexuality (e.g., self-report scales), more objective indicators, but still selfreported measures of hypersexuality should be examined. More objective, but still self-reported indicators can be assessed by the number of sex partners, the frequency of having sex, masturbation, pornography viewing, cybersex, visiting strip clubs and the duration of engagement 
in these activities (Grubbs et al., 2017; Kafka, 2010). In the present study, the self-reported characteristics of sexual life were observed as more objective indicators of hypersexuality that demonstrated that LGBTQ males had the highest number of sexual partners and casual sexual partners in their lifetime. Moreover, they had the highest frequency of having sex with casual sex partners, masturbation, pornography viewing and they spent the most time with pornography viewing per session. Additionally, they had the lowest frequency of having sex with their significant other. These more objective (although still self-reported) indicators of hypersexuality might also imply that LGBTQ males are a group most at risk of developing hypersexuality because they had the least frequent sex in their relationship but they were the most sexually active outside the relationship. However, it should be noted that among LGBTQ males, that as well as monogamous relationships, monogamish and open relationships are also prevalent which can explain the higher frequency of casual partners. LGBTQ males in monogamish and open relationships are similarly satisfied with their relationship, and there are also no significant differences in other relationship qualities as well compared to LGBTQ males in monogamous relationships (Parsons, Startks, Garamel, \& Grov, 2012; Rubel \& Bogaert, 2015; Séguin et al., 2016; Whitton, Weitbrecht, \& Kuryluk, 2015). Moreover, it should be taken into consideration that according to previous results (Parsons et al., 2013), there are more highly sexually active LGBTQ males without hypersexuality (approximately 80\%) than highly sexually active LGBTQ males with hypersexuality (approximately 20\%). Furthermore, according to a largescale, comparison study of hypersexual men (i.e., Stulhofer, Jurin, \& Briken, 2016), men with high sexual desire, and other participants, in some characteristics (e.g., frequency of masturbation and frequency of pornography use), there were no significant differences between hypersexual men and men with high sexual desire. However, in other characteristics of sexual life (e.g., frequency of sexual activity) men with high sexual desire had significantly higher scores than men with 
hypersexuality. Another study reported that hypersexuality was not related to the frequency of having sex with the partner in a sample of gay men (Starks, Grov, \& Parsons, 2013). Therefore, the characteristics of sexual life (e.g., frequency of sexual activities or number of sexual partners) are not reliable indicators of hypersexuality without the negative affect and the consequences of the given behavior.

A possible reason for the high scores of hypersexuality among LGBTQ men could be that these men have to face more obstacles when dating and forming romantic relationships than heterosexuals, therefore it is easier to them to masturbate, to access pornography, and/or to have casual relationships (Montgomery-Graham, 2017; Muench, \& Parsons, 2004). Another explanation could be related to the stereotypes, negative discrimination, and critiques LGBTQ men have to deal with in their everyday life. Consequently, they may consider sex-related activities as a coping strategy that provides fast, easily accessible, affordable and anonymous ways of stress relief and negative emotion reduction (Cooper, 1998). Furthermore, it should also be noted that the frequency of different sexual activities or number of sexual partners per se are not reliable indicators of hypersexuality (Parsons et al., 2013, Stulhofer et al., 2016). This information should be viewed as complementary data alongside the scores on hypersexuality measures because a wide range of variability in type and frequency of sexual activities can be considered healthy (e.g., Balon, Segraves, \& Clayton, 2007; Winters, 2010).

In the literature, cognitive-behavioral therapy, acceptance and commitment therapy, experiential therapy, motivational interviewing, art therapy, mindfulness, relational therapy, peer support groups, or pharmacotherapy have been described as effective approaches to reduce the level of hypersexual disorder and its consequences (e.g., Franqué, Klein, \& Briken, 2015; Grubbs et al., 2017; Stewart \& Federoff, 2014; Van Gordon, Shonin \& Griffiths, 2016). However, to the present authors' best knowledge, no previous research examined whether these psychotherapeutic 
techniques are similarly effective in different groups of individuals with hypersexual disorder. According to the findings of the present study, for LGBTQ individuals, more emphasis should be put on the promotion of other, more adaptive coping strategies, especially in the case of LGBTQ women, who had relatively higher scores on the coping dimension than on the other ones. In previous studies (Hook et al., 2015; Reid, Bramen, Anderson, \& Cohen, 2014; Reid, Temko, Moghaddam, \& Fong, 2014), individuals with HB reported lower levels of mindfulness, selfcompassion, and self-forgiveness indicating that interventions focusing on mindfulness, selfcompassion and self-forgiveness related coping strategies could contribute to more adaptive responses to stressful life events and, therefore, could lead to the reduction of HB (Grubbs et al., 2017; Van Gordon et al., 2016).

Despite the study being comprehensive and largescale, it is important to note that the present study has some limitations. The study is a single, cross-sectional, non-representative survey. Due to the use of this methodology, causality cannot be inferred. Although anonymous data collection is beneficial in sexuality-related studies, considering the fact that anonymity could decrease stress and could result in more honest responses, participants were recruited online, where the real identity of the respondents can perhaps be questioned. The scales assessed selfreported ratings, which may distort the reality (e.g., individuals can perceive their behavior as problematic, even though there is no objective evidence for it being problematic). In future studies, the examination of problematic behaviors (e.g., problematic pornography use, Bőthe et al., 2018) instead of the frequency of the given activity might be beneficial. Although participants were aged between 18 and 76 years, the survey excluded those who did not use the Internet. It would be useful for non-Internet users to be surveyed in future research. A further bias that could distort the results was the inclusion of asexual individuals in the LGBTQ group in the present study. Because asexuality is defined as the lack of sexual attraction (Bogaert, 2004), it is possible 
that the inclusion of asexual individuals might have decreased the levels of hypersexuality and sexuality-related variables (e.g., frequency of pornography viewing, number of sexual partners, etc.). However, the ratio of asexual individuals was very low $(0.1 \%)$.

\section{Conclusions}

Hypersexuality is becoming a widely studied problematic behavior, but further research is needed to confirm and consolidate the existing findings in the field. According to previous reviews (Marshall \& Briken, 2010; Montgomery-Graham, 2017; Stewart \& Fedoroff, 2014) and the present findings, the Hypersexual Behavior Inventory can be reliably employed in diverse populations to assess the extent of hypersexuality. LGBTQ males are a group most at risk of developing hypersexual disorder, but it should be noted that LGBTQ females are also at risk of engaging in hypersexual activities most likely due to coping problems.

Compliance with Ethical Standards

Ethical approval: All procedures performed in studies involving human participants were in accordance with the ethical standards of the institutional and/or national research committee and with the 1964 Helsinki declaration and its later amendments or comparable ethical standards.

Informed consent: Informed consent was obtained from all individual participants included in the study.

\section{Conflict of interest}

The authors declare no conflict of interest. 


\section{REFERENCES}

American Psychiatric Association. (2013). Diagnostic and statistical manual of mental disorders (5th ed.). Washington, DC: Author.

Balon, R., Segraves, R. T., \& Clayton, A. (2007). Issues for DSM-V: Sexual dysfunction, disorder, or variation along normal distribution: Toward rethinking DSM criteria of sexual dysfunctions. American Journal of Psychiatry, 164(2), 198-200. doi: 10.1176/ajp.2007.164.2.198

Beaton, D. E., Bombardier, C., Guillemin, F., \& Ferraz, M. B. (2000). Guidelines for the process of cross-cultural adaptation of self-report measures. Spine, 25(24), 3186-3191.

Bentler, P. M. (1990). Comparative fit indexes in structural models. Psychological Bulletin, 107(2), 238-246. doi: 10.1037/0033-2909.107.2.238

Bogaert, A. F. (2004). Asexuality: Prevalence and associated factors in a national probability sample. Journal of Sex Research, 41(3), 279-287. doi: 10.1080/00224490409552235

Bőthe, B., Tóth-Király, I., Zsila, Á., Griffiths, M. D., Demetrovics, Z., \& Orosz, G. (2018). The Development of the Problematic Pornography Consumption Scale (PPCS). Journal of Sex Research, 55(3) 395-406. doi: 10.1080/00224499.2017.1291798

Brown, T. A. (2015). Confirmatory factor analysis for applied research (second edition). New York, NY: Guilford Press.

Browne, M. V., \& Cudeck, R. (1993). Alternative ways of assessing model fit. In K. A. Bollen, \& J. S. Long (Eds.), Testing structural equation models (pp. 136-162). Newbury Park, CA: Sage.

Chen, F. F. (2007). Sensitivity of goodness of fit indexes to lack of measurement invariance. Structural Equation Modeling, 14(3), 464-504. doi: 10.1080/10705510701301834 
Cheung, G. W., \& Rensvold, R. B. (2002). Evaluating goodness-of-fit indexes for testing measurement invariance. Structural Equation Modeling, 9(2), 233-255. doi: 10.1207/S15328007SEM0902_5

Cooper, A. (1998). Sexuality and the Internet: Surfing into the new millennium. CyberPsychology \& Behavior, 1(2), 187-193. doi: 10.1089/cpb.1998.1.187

Cooper, A., Delmonico, D. L., \& Burg, R. (2000). Cybersex users, abusers, and compulsives: New findings and implications. Sexual Addiction \& Compulsivity, 7(1-2), 5-29. doi: $10.1080 / 10720160008400205$

Dhuffar, M. \& Griffiths, M. D. (2014). Understanding the role of shame and its consequences in female hypersexual behaviours: A pilot study. Journal of Behavioral Addictions, 3, 231237. doi: 10.1556/JBA.3.2014.4.4

Dhuffar, M. K., \& Griffiths, M. D. (2016). Barriers to female sex addiction treatment in the UK. Journal of Behavioral Addictions, 5(4), 562-567. doi: 10.1556/2006.5.2016.072

Finney, S. J., \& DiStefano, C. (2006). Non-normal and categorical data in structural equation modeling. In G. R. Hancock and R. D. Mueller (Eds.), Structural equation modeling: A second course (pp. 269-314). Charlotte, NC: Information Age Publishing.

Franqué, F., Klein, V., \& Briken, P. (2015). Which techniques are used in psychotherapeutic interventions for nonparaphilic hypersexual behavior? Sexual Medicine Reviews, 3(1), 310. doi: $10.1002 /$ smrj.34

Goodman, A. (1993). Diagnosis and treatment of sexual addiction. Journal of Sex \& Marital Therapy, 18, 303-314. doi: 10.1080/00926239308404908

Griffiths, M. D. \& Dhuffar, M. (2014). Treatment of sexual addiction within the British National Health Service. International Journal of Mental Health and Addiction, 12, 561-571. doi: 10.1007/s11469-014-9485-2 
Grubbs, J. B., Hook, J. P., Griffin, B. J., Cushman, M. S., Hook, J. N., \& Penberthy, J. K. (2017). Treating hypersexuality. In Z. D. Peterson (Ed.), The Wiley Handbook of Sex Therapy (pp. 115-128). Chichester: Wiley.

Hook, J. N., Farrell, J. E., Davis, D. E., Van Tongeren, D. R., Griffin, B. J., Grubbs, J., ... Bedics, J. D. (2015). Self- forgiveness and hypersexual behavior. Sexual Addiction and Compulsivity, 22, 59-70. doi:10.1080/10720162.2014.1001542

Hook, J. N., Hook, J. P., Davis, D. E., Worthington, E. L., \& Penberthy, J. K. (2010). Measuring sexual addiction and compulsivity: A critical review of instruments. Journal of Sex \& Marital Therapy, 36, 227-260.

Hu, L., \& Bentler, P. M. (1999). Cutoff criteria for fit indexes in covariance structure analysis: Conventional criteria versus new alternatives. Structural Equation Modeling, 6(1), 1-55. doi: 10.1080/10705519909540118

Kafka, M. P. (2010). Hypersexual disorder: A proposed diagnosis for DSM-V. Archives of Sexual Behavior, 39(2), 377-400. doi: 10.1007/s10508-009-9574-7

Kafka, M. P., \& Hennen, J. (1999). The paraphilia-related disorders: An empirical investigation of nonparaphilic hypersexuality disorders in outpatient males. Journal of Sex \& Marital Therapy, 25(4), 305-319. doi: 10.1080/00926239908404008

Kinsey, A. C., Pomeroy, W. B., \& Martin, C. E. (1948). Sexual behavior in the human male. Philadelphia: W.B. Saunders Company.

Klein, V., Rettenberger, M., Boom, K. D., \& Briken, P. (2014). Eine Validierungsstudie der deutschen Version des Hypersexual Behavior Inventory (HBI). PPmP-Psychotherapie. Psychosomatik Medizinische Psychologie, 64(03/04), 136-140. doi: 10.1055/s-00331357133 
Kline, R. B. (2011). Principles and practice of structural equation modeling (3rd ed.). Methodology in the social sciences. New York: Guilford Press.

Kraus, S. W., Martino, S., \& Potenza, M. N. (2016). Clinical characteristics of men interested in seeking treatment for use of pornography. Journal of Behavioral Addictions, 5(2), 169-178. doi: $10.1556 / 2006.5 .2016 .036$

Langström, N., \& Hanson, R. K. (2006). High rates of sexual behavior in the general population: Correlates and predictors. Archives of Sexual Behavior, 35(1), 37-52. doi: 10.1007/s10508006-8993-y

Levaque, E., Sawatsky, M. L., \& Lalumière, M. L. (2016). Hypersexualité chez les étudiants universitaires hétérosexuels. Canadian Journal of Behavioural Science/Revue Canadienne des Sciences du Comportement, 48(3), 182. doi: 10.1037/cbs0000042

Marsh, H. W., \& Hau, K. T. (2007). Applications of latent-variable models in educational psychology: The need for methodological-substantive synergies. Contemporary Educational Psychology, 32(1), 151-170. doi: 10.1016/j.cedpsych.2006.10.008

Marsh, H. W., Muthén, B., Asparouhov, T., Lüdtke, O., Robitzsch, A., Morin, A. J. S., et al. (2009). Exploratory structural equation modeling, integrating CFA and EFA: Application to students' evaluations of university teaching. Structural Equation Modeling: A Multidisciplinary Journal, 16(3), 439-476. doi: 10.1080/10705510903008220

Marshall, L. E., \& Briken, P. (2010). Assessment, diagnosis, and management of hypersexual disorders. Current Opinion in Psychiatry, 23(6), 570-573. doi: 10.1097/YCO.0b013e32833d15d1

Meredith, W., \& Teresi, J. A. (2006). An essay on measurement and factorial invariance. Medical Care, 44(11), S69-S77. doi: 10.1097/01.mlr.0000245438.73837.89 
Missildine, W., Feldstein, G., Punzalan, J. C., \& Parsons, J. T. (2005). S/he loves me, s/he loves me not: Questioning heterosexist assumptions of gender differences for romantic and sexually motivated behaviors. Sexual Addiction \& Compulsivity, 12(1), 65-74. doi: $0.1080 / 10720160590933662$

Montgomery-Graham, S. (2017). Conceptualization and assessment of hypersexual disorder: A systematic review of the literature. Sexual Medicine Reviews, 5(2), 146-162. doi: 10.1016/j.sxmr.2016.11.001

Muench, F., \& Parsons, J. T. (2004). Sexual compulsivity and HIV: Identification and treatment. Focus, 19(6), 1-5.

Muthén, L. K., \& Muthén, B. O. (1998-2015). Mplus User’s Guide. Seventh Edition. Los Angeles, CA: Muthén \& Muthén.

Nunnally, J. C. (1978). Psychometric theory (2 ${ }^{\text {nd }}$ ed.). New York, NY: McGraw-Hill.

Parsons, J. T. (2005). HIV-positive gay and bisexual men. In S. Kalichman (Ed.), Positive prevention (pp. 99-133). New York: Springer.

Parsons, J. T., Kelly, B. C., Bimbi, D. S., Muench, F., \& Morgenstern, J. (2007). Accounting for the social triggers of sexual compulsivity. Journal of Addictive Diseases, 26(3), 5-16. doi: 10.1300/J069v26n03_02

Parsons, T., Kelly, B. C., Bimbi, D. S., DiMaria, L, Wainberg, M. L, \& Morgenstern, J. (2008). Explanations for the origins of sexual compulsivity among gay and bisexual men. Archives of Sexual Behavior, 37, 817-826. doi: 10.1007/s10508-007-9218-8

Parsons, J. T., Rendina, H. J., Ventuneac, A., Cook, K. F., Grov, C., \& Mustanski, B. (2013). A psychometric investigation of the Hypersexual Disorder Screening Inventory among 
highly sexually active gay and bisexual men: An item response theory analysis. Journal of Sexual Medicine, 10(12), 3088-3101. doi: 10.1111/jsm.12117

Parsons, J. T., Starks, T. J., Gamarel, K. E., \& Grov, C. (2012). Non-monogamy and sexual relationship quality among same-sex male couples. Journal of Family Psychology, 26(5), 669.

Reid, R. C. (2015). How should severity be determined for the DSM-5 proposed classification of Hypersexual Disorder? Journal of Behavioral Addictions, 4(4), 221-225. doi: $10.1556 / 2006.4 .2015 .041$

Reid, R. C. \& Kafka, M. P. (2014). Controversies about Hypersexual Disorder and the DSM-5. Current Sexual Health Reports, 6, 259-264.

Reid, R. C., Bramen, J. E., Anderson, A., \& Cohen, M. S. (2014). Mindfulness, emotional dysregulation, impulsivity, and stress proneness among hypersexual patients. Journal of Clinical Psychology, 70, 313-321. doi:10.1002/jclp.22027

Reid, R. C., Carpenter, B. N., \& Lloyd, T. Q. (2009). Assessing psychological symptom patterns of patients seeking help for hypersexual behavior. Sexual and Relationship Therapy, 24(1), 47-63. doi: 10.1080/14681990802702141

Reid, R. C., Dhuffar, M. K., Parhami, I., \& Fong, T. W. (2012). Exploring facets of personality in a patient sample of hypersexual women compared with hypersexual men. Journal of Psychiatric Practice, 18(4), 262-268. doi: 10.1097/01.pra.0000416016.37968.eb

Reid, R. C., Garos, S., \& Carpenter, B. N. (2011). Reliability, validity, and psychometric development of the Hypersexual Behavior Inventory in an outpatient sample of men. Sexual Addiction \& Compulsivity, 18(1), 30-51. doi: 10.1080/10720162.2011.555709 
Reid, R. C., Temko, J., Moghaddam, J. F., \& Fong, T. W. (2014). Shame, rumination, and selfcompassion in men assessed for hypersexual disorder. Journal of Psychiatric Practice, 20, 260-268. doi:10.1097/01.pra.0000452562.98286.c5

Reid, R. C., Carpenter, B. N., Hook, J. N., Garos, S., Manning, J. C., Gilliland, R., Cooper, E. B....Fong, T. (2012). Report of findings in a DSM-5 field trial for hypersexual disorder. Journal of Sexual Medicine, 9, 2868-2877. doi: 10.1111/j.1743-6109.2012.02936.x

Rubel, A. N., \& Bogaert, A. F. (2015). Consensual nonmonogamy: Psychological well-being and relationship quality correlates. Journal of Sex Research, 52(9), 961-982. doi: $10.1080 / 00224499.2014 .942722$

Schermelleh-Engel, K., Moosbrugger, H., \& Müller, H. (2003). Evaluating the fit of structural equation models: Tests of significance and descriptive goodness-of-fit measures. Methods of Psychological Research Online, 8(2), 23-74.

Seegers, J. A. (2003). The prevalence of sexual addiction symptoms on the college campus. Sexual Addiction \& Compulsivity, 10(4), 247-258. doi: 10.1080/713775413

Séguin, L. J., Blais, M., Goyer, M. F., Adam, B. D., Lavoie, F., Rodrigue, C., \& Magontier, C. (2017). Examining relationship quality across three types of relationship agreements. Sexualities, 20(1-2), 86-104. doi: 10.1177/1363460716649337

Stark, R., Kruse, O., Klucken, T., Strahler, J., \& Wehrum-Osinsky, S. (2017). OP-107:

Distractibility by sexual stimuli--a biological marker of hypersexuality? Journal of Behavioral Addictions, 6(S1), 50-51. doi: 10.1556/JBA.6.2017.Suppl.1

Starks, T. J., Grov, C., \& Parsons, J. T. (2013). Sexual compulsivity and interpersonal functioning: Sexual relationship quality and sexual health in gay relationships. Health Psychology, 32(10), 1047-1056. 
Stewart, H., \& Fedoroff, J. P. (2014). Assessment and treatment of sexual people with complaints of hypersexuality. Current Sexual Health Reports, 6(2), 136-144. doi: 10.1007/s11930014-0017-7

Štulhofer, A., Jurin, T., \& Briken, P. (2016). Is high sexual desire a facet of male hypersexuality? Results from an online study. Journal of Sex \& Marital Therapy, 42(8), 665-680. doi: 10.1080/0092623X.2015.1113585

Tabachnick, B. G., \& Fidell, L. S. (2001). Using multivariate statistics (4th ed.). Boston, MA: Allyn and Bacon.

Tóth-Király, I., Bőthe, B., Rigó, A., \& Orosz, G. (2017). An Illustration of the Exploratory Structural Equation Modeling (ESEM) Framework on the Passion Scale. Frontiers in Psychology, 8:1968. doi: 10.3389/fpsyg.2017.01968

Vandenberg, R. J., \& Lance, C. E. (2000). A review and synthesis of the measurement invariance literature: Suggestions, practices, and recommendations for organizational research. Organizational Research Methods, 3(1), 4-70. doi: 10.1177/10944281003100

Van Gordon, W., Shonin, E., \& Griffiths, M. D. (2016). Meditation Awareness Training for the treatment of sex addiction: A case study. Journal of Behavioral Addictions, 5, 363-372. doi: $10.1556 / 2006.5 .2016 .034$

Volberg, R. A. (1994). The prevalence and demographics of pathological gamblers: implications for public health. American Journal of Public Health, 84(2), 237-241. doi: 10.2105/AJPH.84.2.237

Wéry, A., Vogelaere, K., Challet-Bouju, G., Poudat, F. X., Caillon, J., Lever, D., ... \& GrallBronnec, M. (2016). Characteristics of self-identified sexual addicts in a behavioral addiction outpatient clinic. Journal of Behavioral Addictions, 5(4), 623-630. doi: $10.1556 / 2006.5 .2016 .071$ 
Whitton, S. W., Weitbrecht, E. M., \& Kuryluk, A. D. (2015). Monogamy agreements in male same-sex couples: Associations with relationship quality and individual wellbeing. Journal of Couple \& Relationship Therapy, 14(1), 39-63. doi: $10.1080 / 15332691.2014 .953649$

Winters, J. (2010). Hypersexual disorder: A more cautious approach. Archives of Sexual Behavior, 39(3), 594-596. doi: 10.1007/s10508-010-9607-2

Winters, J., Christoff, K., \& Gorzalka, B. B. (2010). Dysregulated sexuality and high sexual desire: Distinct constructs? Archives of Sexual Behavior, 39(5), 1029-1043. doi: $10.1007 / \mathrm{s} 10508-009-9591-6$

Womack, S. D., Hook, J. N., Ramos, M., Davis, D. E., Penberthy, J. K. (2013). Measuring hypersexual behavior. Sexual Addiction \& Compulsivity, 20 (1-2), 65-78.

Yeagley, E., Hickok, A., \& Bauermeister, J. A. (2014). Hypersexual behavior and HIV sex risk among young gay and bisexual men. Journal of Sex Research, 51(8), 882-892. doi: $10.1080 / 00224499.2013 .818615$ 
Table 1. Prior validity and reliability characteristics of the Hypersexual Behavior Inventory $\dagger$

\begin{tabular}{|c|c|c|c|c|c|c|c|c|c|c|c|}
\hline Authors (year) & Nation & Sample & Analysis & Characteristics & Coping & Control & Consequences & CFI & TLI & RMSEA & Final model \\
\hline \multirow{3}{*}{$\begin{array}{l}\text { Klein et al. } \\
\text { (2014) }\end{array}$} & \multirow{3}{*}{ Germany } & \multirow{3}{*}{$\begin{array}{l}\mathrm{N}=1749(57 \% \text { females }) \\
\mathrm{M}_{\text {age }}=24.42(\mathrm{SD}=4.38)\end{array}$} & \multirow{3}{*}{ CFA } & Number of items & 7 & 8 & 4 & \multirow{3}{*}{.90} & \multirow{3}{*}{-} & \multirow{3}{*}{.07} & \multirow{3}{*}{ 3-factor } \\
\hline & & & & Average loadings & - & - & - & & & & \\
\hline & & & & Cronbach's alpha & .86 & .83 & .78 & & & & \\
\hline \multirow{6}{*}{$\begin{array}{l}\text { Reid et al. } \\
\quad(2011)\end{array}$} & \multirow{3}{*}{$\begin{array}{l}\text { United } \\
\text { States of } \\
\text { America }\end{array}$} & \multirow{3}{*}{$\begin{array}{c}\mathrm{N}=324(0 \% \text { females }) \\
\mathrm{M}_{\mathrm{age}}=32(\mathrm{SD}=-)\end{array}$} & \multirow{3}{*}{ EFA } & Number of items & 7 & 8 & 4 & \multirow{3}{*}{-} & \multirow{3}{*}{-} & \multirow{3}{*}{-} & \multirow{3}{*}{3 -factor } \\
\hline & & & & Average loadings & .72 & .67 & .67 & & & & \\
\hline & & & & Cronbach's alpha & .90 & .94 & .87 & & & & \\
\hline & \multirow{3}{*}{$\begin{array}{l}\text { United } \\
\text { States of } \\
\text { America }\end{array}$} & \multirow{3}{*}{$\begin{array}{c}\mathrm{N}=203(0 \% \text { females }) \\
\mathrm{M}_{\mathrm{age}}=33(\mathrm{SD}=-)\end{array}$} & \multirow{3}{*}{ CFA } & Number of items & 7 & 8 & 4 & \multirow{3}{*}{.95} & \multirow{3}{*}{-} & \multirow{3}{*}{.06} & \multirow{3}{*}{3 -factor } \\
\hline & & & & Average loadings & .82 & .84 & .80 & & & & \\
\hline & & & & Cronbach's alpha & .91 & .95 & .89 & & & & \\
\hline \multirow{3}{*}{$\begin{array}{l}\text { Yeagley et al. } \\
\quad(2014)\end{array}$} & \multirow{3}{*}{$\begin{array}{l}\text { United } \\
\text { States of } \\
\text { America }\end{array}$} & \multirow{3}{*}{$\begin{array}{c}\mathrm{N}=366(0 \% \text { females }) \\
\mathrm{M}_{\mathrm{age}}=21.46(\mathrm{SD}=1.95)\end{array}$} & \multirow{3}{*}{ CFA } & Number of items & 4 & 5 & 2 & \multirow{3}{*}{.99} & \multirow{3}{*}{-} & \multirow{3}{*}{.05} & \multirow{3}{*}{ 3-factor } \\
\hline & & & & Average loadings & .81 & .83 & .86 & & & & \\
\hline & & & & Cronbach's alpha & .88 & .92 & .83 & & & & \\
\hline
\end{tabular}

Note $. \dagger=$ Literature search was performed on February 05, 2018; $\mathrm{M}_{\text {age }}=$ mean age; $\mathrm{N}=$ number of participants; CFA = confirmatory factor analysis; $\mathrm{EFA}=$ exploratory factor analysis; $\mathrm{N}$ of items = number of items; $\mathrm{CFI}=$ comparative fit index; TLI = Tucker-Lewis Index; RMSEA = root-mean-square error of approximation. 
Table 2. Tests of gender and sexual orientation invariance on the Hypersexual Behavior Inventory

\begin{tabular}{|c|c|c|c|c|c|c|c|c|c|c|}
\hline Model & WLSMV $\chi^{2}(\mathrm{df})$ & CFI & TLI & RMSEA & $90 \% \mathrm{CI}$ & Comparison & $\Delta \chi^{2}(\mathrm{df})$ & $\Delta \mathrm{CFI}$ & $\Delta \mathrm{TLI}$ & $\triangle \mathrm{RMSEA}$ \\
\hline CFA 3-factor first-order model & $13718.625^{*}(149)$ & .940 & .931 & .071 & $.070-.072$ & - & - & - & - & - \\
\hline \multicolumn{11}{|c|}{ Gender invariance } \\
\hline Baseline male & $9539.656 *(149)$ & .941 & .932 & .073 & $.072-.074$ & - & - & - & - & - \\
\hline Baseline female & $4858.204 *(149)$ & .927 & .917 & .072 & $.070-.074$ & - & - & - & - & - \\
\hline M1. Configural & $14248.170 *(298)$ & .939 & .929 & .072 & $.071-.073$ & - & - & - & - & - \\
\hline M2. Metric & $14717.090 *(314)$ & .937 & .931 & .072 & $.071-.073$ & M2-M1 & $555.101 *(16)$ & -.002 & +.002 & .000 \\
\hline M3. Scalar & $13678.440 *(368)$ & .941 & .946 & .064 & $.063-.064$ & M3-M2 & $485.325 *(54)$ & +.004 & +.015 & -.008 \\
\hline M4. Residual & $12918.392 *(387)$ & .945 & .951 & .060 & $.059-.061$ & M4-M3 & $339.467 *(19)$ & +.004 & +.005 & -.004 \\
\hline M5. Latent variance-covariance & $6889.346^{*}(393)$ & .971 & .975 & .043 & $.042-.044$ & M5-M4 & $33.539 *(6)$ & +.026 & +.024 & -.017 \\
\hline M6. Latent means & $9087.688 *(396)$ & .962 & .967 & .049 & $.049-.050$ & M6-M5 & $708.128 *(3)$ & -.009 & -.008 & +.006 \\
\hline \multicolumn{11}{|c|}{ Sexual orientation invariance } \\
\hline Baseline heterosexual & $10854.656^{*}(149)$ & .940 & .931 & .069 & $.068-.070$ & - & - & - & - & - \\
\hline Baseline LGBTQ & $2939.128 *(149)$ & .938 & .929 & .08 & $.077-.082$ & - & - & - & - & - \\
\hline M1. Configural & $13694.847 *(298)$ & .938 & .928 & .071 & $.070-.072$ & - & - & - & - & - \\
\hline M2. Metric & $13879.712 *(314)$ & .937 & .931 & .069 & $.068-.070$ & M2-M1 & $201.713 *(16)$ & -.001 & +.003 & -.002 \\
\hline M3. Scalar & $12784.658 *(368)$ & .942 & .946 & .061 & $.060-.062$ & M3-M2 & $177.672 *(54)$ & +.005 & +.015 & -.008 \\
\hline M4. Residual & $1135.205^{*}(387)$ & .949 & .955 & .056 & $.055-.057$ & M4-M3 & $75.627 *(19)$ & +.007 & +.009 & -.005 \\
\hline M5. Latent variance-covariance & $5481.281 *(393)$ & .976 & .979 & .038 & $.037-.039$ & M5-M4 & $26.778 *(6)$ & +.027 & +.024 & -.018 \\
\hline M6. Latent means & $7337.040 *(396)$ & .968 & .972 & .044 & $.043-.045$ & M6-M5 & $570.744 *(3)$ & -.008 & -.007 & +.006 \\
\hline \multicolumn{11}{|c|}{ Gender and sexual orientation invariance } \\
\hline Baseline heterosexual male & $7781.602 *(149)$ & .942 & .933 & .070 & $.069-.072$ & - & - & - & - & - \\
\hline Baseline LGBTQ male & $1748.908 *(149)$ & .936 & .927 & .087 & $.083-.090$ & - & - & - & - & - \\
\hline Baseline heterosexual female & $3597.855 *(149)$ & .921 & .909 & .071 & $.069-.073$ & - & - & - & - & - \\
\hline Baseline LGBTQ female & $1435.119 *(149)$ & .933 & .923 & .076 & $.072-.080$ & - & - & - & - & - \\
\hline
\end{tabular}




\begin{tabular}{|c|c|c|c|c|c|c|c|c|c|c|}
\hline M1. Configural & $14238.264 *(596)$ & .936 & .927 & .071 & $.070-.072$ & - & - & - & - & - \\
\hline M2. Metric & $14905.906 *(644)$ & .934 & .929 & .070 & $.069-.071$ & M2-M1 & $788.817 *(48)$ & -.002 & +.002 & -.001 \\
\hline M3. Scalar & $13907.647 *(806)$ & .939 & .948 & .060 & $.059-.061$ & M3-M2 & $803.312 *(162)$ & +.005 & +.019 & -.010 \\
\hline M4. Residual & $12857.928 *(863)$ & .944 & .956 & .056 & $.055-.057$ & M4-M3 & $425.574 *(57)$ & +.005 & +.008 & -.004 \\
\hline M5. Latent variance-covariance & $6814.007 *(881)$ & .972 & .979 & .039 & $.038-.040$ & M5-M4 & $78.145 *(18)$ & +.028 & +.023 & -.017 \\
\hline M6. Latent means & $11520.841 *(890)$ & .950 & .962 & .052 & $.051-.052$ & M6-M5 & $1496.022 *(9)$ & -.022 & -.017 & +.013 \\
\hline
\end{tabular}

Note. WLSMV = weighted least squares mean- and variance-adjusted estimator; $\chi^{2}=\mathrm{Chi}$-square; $\mathrm{df}=\mathrm{degrees}$ of freedom; CFI =

comparative fit index; TLI = Tucker-Lewis Index $;$ RMSEA = root-mean-square error of approximation; $90 \% \mathrm{CI}=90 \%$ confidence interval of the RMSEA; $\triangle \mathrm{CFI}=$ change in CFI value compared to the preceding model; $\triangle \mathrm{TLI}=$ change in the TLI value compared to the preceding model; $\triangle \mathrm{RMSEA}=$ change in the RMSEA value compared to the preceding model; Bold letters indicate the final levels of invariance that were achieved. ${ }^{*} p<.001$. 
Table 3. Latent means comparison between groups based on gender and sexual orientation

\begin{tabular}{|c|c|c|c|c|}
\hline Latent variables & $\begin{array}{l}\text { Heterosexual } \\
\text { males }\end{array}$ & LGBTQ males & $\begin{array}{l}\text { Heterosexual } \\
\text { females }\end{array}$ & LGBTQ females \\
\hline HBI Coping & 0.00 & $+0.30(.03)$ & $-0.15(.02)$ & $+0.20(.03)$ \\
\hline HBI Control & 0.00 & $+0.63(.03)$ & $-0.39(.02)$ & $+0.03(.03)$ \\
\hline HBI Consequences & 0.00 & $+0.43(.04)$ & $-0.62(.02)$ & $-0.16(.04)$ \\
\hline HBI Coping & $-0.30(.03)$ & 0.00 & $-0.45(.03)$ & $-0.11(.04)$ \\
\hline HBI Control & $-0.63(.03)$ & 0.00 & $-1.01(.04)$ & $-0.59(.04)$ \\
\hline HBI Consequences & $-0.43(.04)$ & 0.00 & $-1.05(.04)$ & $-0.59(.05)$ \\
\hline HBI Coping & $+0.15(.02)$ & $+0.45(.03)$ & 0.00 & $+0.34(.03)$ \\
\hline HBI Control & $+0.39(.02)$ & $+1.01(.04)$ & 0.00 & $+0.42(.04)$ \\
\hline HBI Consequences & $+0.62(.02)$ & $+1.05(.04)$ & 0.00 & $+0.45(.04)$ \\
\hline HBI Coping & $-0.19(.03)$ & $+0.11(.04)$ & $-0.36(.03)$ & 0.00 \\
\hline HBI Control & $-0.03(.03)$ & $+0.59(.04)$ & $-0.47(.04)$ & 0.00 \\
\hline HBI Consequences & $+0.16(.04)$ & $+0.59(.05)$ & $-0.53(.05)$ & 0.00 \\
\hline
\end{tabular}

Note. Latent means are reported with their standard errors in parentheses. Significant differences

are depicted in bold $(p<0.05)$. Latent means are fixed to zero in one referent group for

identification purposes and latent means estimated in the other three groups reflect deviations

from this referent groups expressed in standard deviation units. HBI Coping = Hypersexual

Behavior Inventory Coping factor; HBI Control = Hypersexual Behavior Inventory Control

factor; HBI Consequences = Hypersexual Behavior Inventory Consequences factor 
Table 4. Comparison of gender and sexual orientation-based groups on the indicators of hypersexuality

\begin{tabular}{|c|c|c|c|c|c|c|c|c|}
\hline & \multirow[b]{2}{*}{ Range } & \multirow{2}{*}{$\begin{array}{c}(1) \\
\begin{array}{c}\text { Heterosexual } \\
\text { males }\end{array} \\
(\mathrm{N}=11052 \\
\mathrm{N}_{\mathrm{d}}=8163 \\
\left.\mathrm{~N}_{\mathrm{e}}=3869\right)\end{array}$} & \multicolumn{3}{|c|}{ (3) } & \multicolumn{3}{|c|}{ ANOVA } \\
\hline & & & $\begin{array}{l}(\mathrm{N}=740 \\
\mathrm{N}_{\mathrm{d}}=391 \\
\left.\mathrm{~N}_{\mathrm{e}}=505\right)\end{array}$ & $\begin{array}{c}\text { temales } \\
(\mathrm{N}=5664 \\
\mathrm{N}_{\mathrm{d}}=4149 \\
\left.\mathrm{~N}_{\mathrm{e}}=1890\right)\end{array}$ & $\begin{array}{l}\text { LGB TQ temales } \\
\qquad \begin{array}{c}(\mathrm{N}=468 \\
\mathrm{N}_{\mathrm{d}}=301 \\
\left.\mathrm{~N}_{\mathrm{e}}=219\right)\end{array}\end{array}$ & $\mathrm{F}$ & $p$ & $\eta^{2}$ \\
\hline number of sexual partners & $1-16^{\mathrm{a}}$ & $8.39(4.40)^{2,3}$ & $10.85(4.52)^{1,3,4}$ & $7.96(4.02)^{1,2,4}$ & $8.63(4.25)^{2,3}$ & 100.71 & $<.001$ & .017 \\
\hline number of casual sexual partners & $1-16^{\mathrm{a}}$ & $5.62(4.62)^{2,3}$ & $9.52(5.10)^{1,3,4}$ & $4.87(3.97)^{1,2,4}$ & $5.82(4.45)^{2,3}$ & 242.62 & $<.001$ & .039 \\
\hline frequency of having sex with the partner & $1-10^{\mathrm{b}}$ & $6.95(1.82)^{2,3}$ & $6.67(2.17)^{1,3,4}$ & $7.31(1.70)^{1,2}$ & $7.15(1.76)^{2}$ & 42.56 & $<.001$ & .010 \\
\hline frequency of having sex with casual partners & $1-10^{\mathrm{b}}$ & $4.07(2.03)^{3}$ & $4.28(1.95)^{3}$ & $3.79(1.83)^{1,2}$ & $3.96(2.00)$ & 12.38 & $<.001$ & .006 \\
\hline frequency of masturbation & $1-10^{b}$ & $7.43(2.14)^{2,3,4}$ & $8.47(1.66)^{1,3,4}$ & $5.60(2.18)^{1,2,4}$ & $6.77(1.98)^{1,2,3}$ & 1039.16 & $<.001$ & .150 \\
\hline frequency of pornography viewing & $1-10^{\mathrm{b}}$ & $7.13(2.36)^{2,3,4}$ & $8.12(1.92)^{1,3,4}$ & $3.87(2.33)^{1,2,4}$ & $5.18(2.40)^{1,2,3}$ & 2459.82 & $<.001$ & .309 \\
\hline duration of pornography viewing per occasion & $0-180^{c}$ & $27.83(21.18)^{2,3,4}$ & $35.76(28.89)^{1,3,4}$ & $21.82(16.51)^{1,2}$ & $24.48(20.20)^{1,2}$ & 130.75 & $<.001$ & .026 \\
\hline
\end{tabular}

Note. ${ }^{\mathrm{a}}=$ 1: 0 partner; 2: 1 partner; 3: 2 partners; 4: 3 partners; 5: 4 partners; 6: 5 partners; 7: 6 partners; 8: 7 partners; 9: 8 partners; 10:

9 partners; 11: 10 partners; 12: 10 partners; 12: 11-20 partners, 13: 21-30 partners; 14: 31-40 partners; 15: 41-50 partners; 16: more than 50 partners; ${ }^{\mathrm{b}}=1:$ never; 2 : once in the last year; 3: 1-6 times in the last year; 4: 7-11 times in the last year; 5: monthly; 6: two or

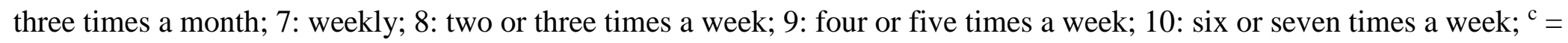
participants indicated their responses in minutes; ${ }_{\mathrm{d}}=$ number of partnered respondents; $\mathrm{e}=$ number of respondents who had casual sexual partners. $\eta^{2}=$ Eta-squared. Superscript numbers $(1,2,3,4)$ indicate significant $(p<.05)$ difference between the given group and the indexed group within the same variable. 
A. Latent mean differences on the HBI factors when Heterosexual males is the referent group

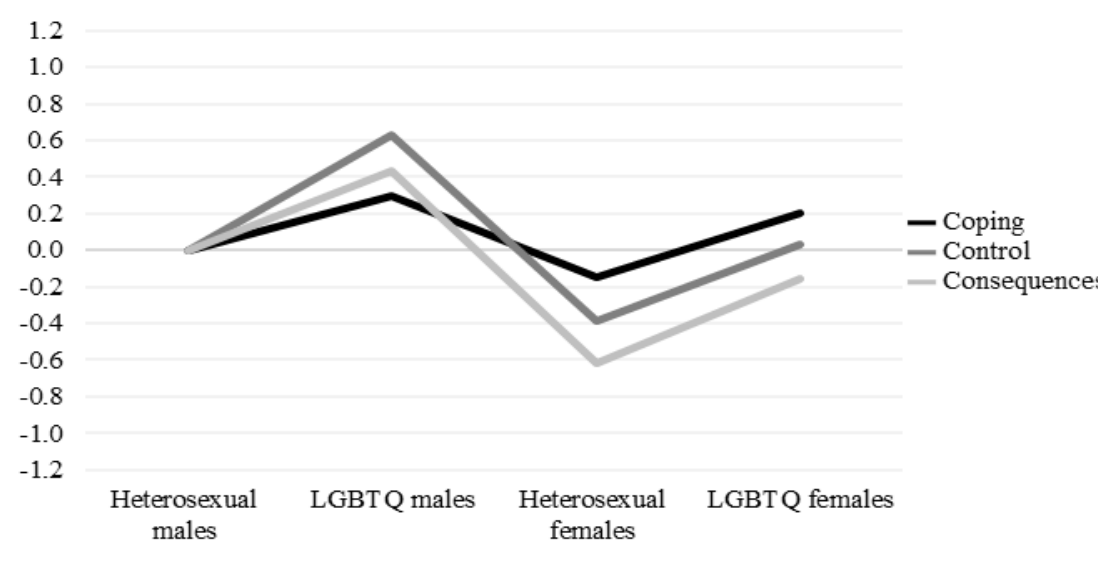

C. Latent mean differences on the HBI factors when Heterosexual females is the referent group

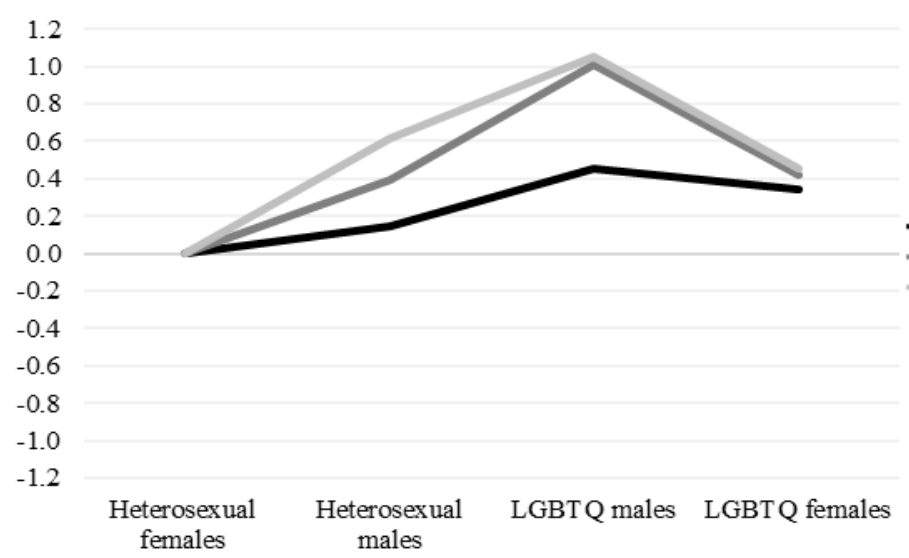

- Consequenc females males
B. Latent mean differences on the HBI factors when LGBTQ males is the referent group

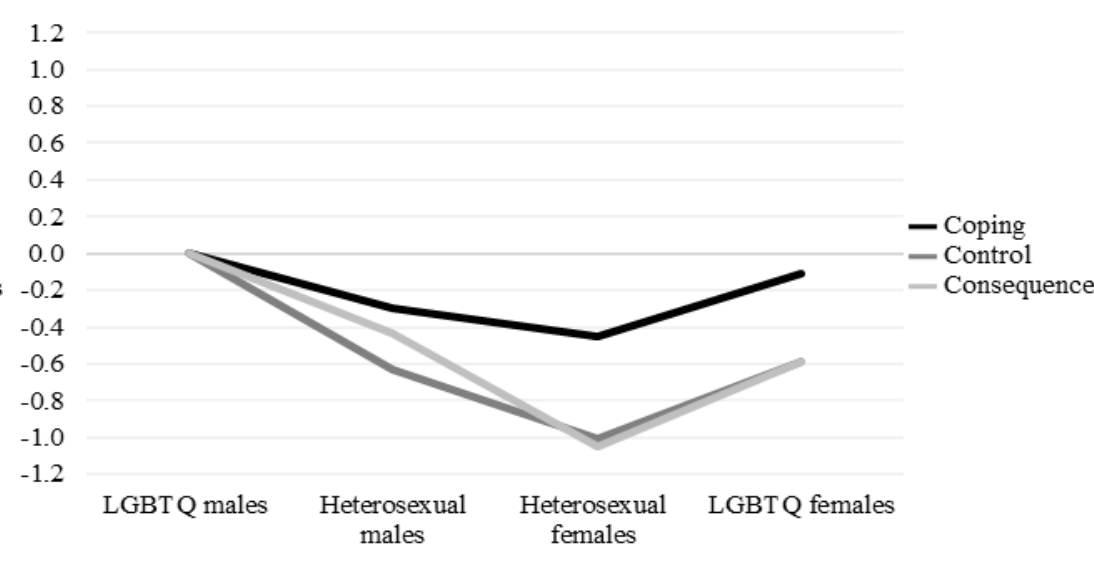

D. Latent mean differences on the HBI factors when LGBTQ females is the referent group

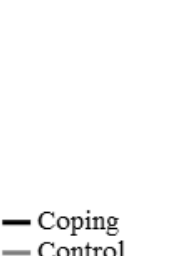

Figure 1. Visualization of latent mean comparisions between groups based on gender and sexual orientation. Note. Latent means are

fixed to zero in one referent group for identification purposes and latent means estimated in the other three groups reflect deviations from this referent groups expressed in standard deviation units. 